\title{
Microbiota and Dermatology
}

\section{(D) Damla Demir' ${ }^{1}$ (1) Erhan Ersoy², (1) ilkin Zindanc ${ }^{2}$}

${ }^{1}$ Medipol University Faculty of Medicine, Department of Dermatology, Istanbul, Turkey

2University of Health Sciences Turkey Faculty of Medicine, Department of Dermatology; Umraniye Training and Research Hospital, Istanbul, Turkey

\section{ABSTRACT}

Barrier structure and function of skin are essential to human health. Skin represents the primary interface between the host and the environment; it is colonized by microorganisms, most of which are harmless or even beneficial to their host. Colonization is driven by the ecology of the skin surface, which is highly variable depending on topographical location, host factors and environmental factors. In recent years, investigations have shown that the microbiome has a major impact on physiological functions including protection against infections, reaction patterns in the immune system, and disposition for inflammation-mediated diseases. An enhanced understanding of the skin microbiome is necessary to gain insight into microbial involvement in human skin disorders and to enable novel therapeutic approaches for their treatment.

Keywords: Microbiota, Microbial interaction, Skin, Immunity, Skin diseases

\section{Introduction}

Microbiota is a term that describes the microorganisms found on all anatomical sites and includes bacteria, viruses and funghi. Microbiome refers to the collection of these microorganisms containing genome [1]. It has been estimated that there are ten times more microbial cells than body cells in humans [2]. We can imagine these microorganisms to be a kind of a microbial organ. Until recently the studies have been focused on microorganisms as agents of disease, but now they are recognized as regulators of the immune system and therefore important factor for the human health [3].

Primary function of the skin, which is the largest organ of the human body, is to act as a barrier against endogenous and exogenous factors. The skin is in direct contact with the external environment and therefore providing a home to various microorganisms.

These microorganisms have a symbiotic relationship with the skin and help maintaining the homeostasis of the skin by regulating the immune system. Disruption of this relationship can lead to various dermatological diseases.
The aim of this review is to evaluate the skin microbiome and it's role in dermatological diseases.

\section{History}

The research of human microbiota in dermatology began with Kligman in 1950 using cell culture method [4]. In 2000 Nobel laureate Joshua Lederberg suggested using the term human microbiome to describe the collective genome of microorganisms colonizing the human body [5]. The International Human Microbiome Consortium launched in 2008 with the mission of generating resources that would enable the characterization of the human microbiome and analysis of its role in human health and disease [6].

\section{Microbiota Development}

Development of microbiota begins with the first day of pregnancy. 'The first 1000 days" refers to the child's life from conception to the end of the $2^{\text {nd }}$ year of life. This time is the most important period for microbiota development. Factors like pregnancy, delivery mode, intrapartum antibiotic use, lactation and maternal dietary 
factors cause temporary or permanent changes on composition of microbiota [7].

Pregnancy is the first step on the development of baby's microbiota. Sequencing analysis of unculturable microorganisms has been used to define microbial composition of placental membranes, amniotic fluid, umblical cords and meconium. The placental microbiota composition has been found similar to the maternal oral microbiota and it's been considered that it can influence the fetal immune tolerance [8]. Maternal dietary factors, maternal body mass index, intrapartum antibiotic use and stress during pregnancy affect maternal microbiota composition. That, in turn, has an effect on the babies microbiota composition and immune system $[8,9]$.

Delivery mode is one of the key factors on the development of microbiota. During vaginal delivery newborn's skin is colonised with the maternal vaginal flora. Skin flora in newborns delivered by Cesarean section (C-section) resembled that of the mother's skin. A study by Dominguez-Bello in 2010 has shown that microbiota compositions of newborns differ between vaginal delivery and C-section. Vaginal delivered infants acquired bacterial communities resembling maternal vaginal microbiota, dominated by Lactobacillus and followed by Atopobium, Prevotella, or Sneathia. Lactobacillus has not been found dominant in C-section delivered infants, on the contrary, their microbiota were dominated by Staphylococcus similar to skin flora [10].

An another research by Martin et al. [11] has shown that in vaginally born infants receiving breast milk, Bifidobacterium dominance occurs in 20 days in contradistinction to six months in C-section delivered infants. In a systematic review, Rutayisire et al. [12] reported that Bifidobacterium, Enterobacteriaceae, Bacteroides and Lactobacillus genera were to be significantly more frequent in vaginally delivered infants compared with CS delivered. Haemophilius, Veillonella, Clostridiaceae ve Klebsiella genera were more frequent in CS delivered infants. Clostridiaceae dominance in microbiota continued to the end of the $2^{\text {nd }}$ month, on the other hand Bifidobacterium and Bacteroides became prominent only after $3^{\text {rd }}$ month.

Another key factor for the early-life development of microbiota is the breastfeeding (8). Studies on breastfeeding have shown that a diverse population of bacteria is present in breast milk (ranging from 100 to $10^{5}$ CFU per $\mathrm{mL}$ depending on the study) and this population differs with the delivery mode and gestational age $[13,14]$. Streptococcus, Staphylococcus, Lactobacillus, Bifidobacterium, Enterococcus, and Propionibacterium were most common but other short-chain fatty acid producing bacteria such as Veillonella, Propionibacterium, and Faecalibacterium have also been isolated from breast milk [15]. Breastfeeding may influence development of immune-mediated diseases through several mechanisms including shaping gut microbiota and thus impacts on immune system [8].

\section{Skin Microbiome}

The skin microbiota conceived of as two microbial groups; permanent residents and transient microorganisms (temporary residents) which arise from the environment and persist for hours to days [16]. Grice and Segre [17] reported that Actinobacteria, Firmicutes, Bacteroidetes and Proteobacteria were dominant in skin microbiota.

Skin microbiota and microbial colonization are dependent on the anatomical and physiology of the skin site $[17,18]$. Human skin consists of 4 microenvironments: dry, moist, sebaceous and other (sweat glands, hair follicles, dermal layers) [19]. Each microenviroment has a distinct microbiota. Corynebacteria, Proteobacteria, Flavobacteriales are dominant on dry areas like forearm and buttock; Corynebacteria, Proteobacteria, Staphylococcus are dominant on moist areas like axillary vault, antecubital and popliteal fossa. Sebaceous microenviroment like face and upper body contains mainly Cutibacterium and Staphylococcus [20]. In addition, a specific microbiome profile has been found not only on the skin surface but also in the deep layers of the epidermis, dermis and dermal fat tissue [21].

The skin microbiome consists not only of bacteria, but also of microorganisms such as fungi, arthropods, viruses (22). Most common fungal species Malassezia spp. are especially prevalent on most of the body and scalp. The Demodex mites, which are microscopic arthropods, are lipophilic. Demodex folliculorum are located in hair follicles; Demodex brevis are located in sebaceous glands and meibomian glands which line the margin of the eyelids [23].

Skin microbiome may differ from person to person. This differences can be divided as intrinsic and extrinsic factors. Intrinsic factors are age, genotype, body temperature and $\mathrm{pH}$ and host immune system. Extrinsic factors are climate, humidity, antibiotic use, clothing choices, detergent and emollient use, surface contact factors such as antiperspirant and frequency of hygiene $[24,25,26,27,28,29,30,31]$.

\section{Skin Microbiota and Immune System}

The skin consists of two layers called "epidermis" and "dermis". The first cells that take an active role in the immune response in the skin are "keratinocytes" in the epidermis. These cells recognize structures of pathogens with pattern recognition receptors (PRR), and produce anti-microbial peptides and cytokines. "Langerhans cells", a special subgroup of dendritic cells, are also located in the epidermis. Dermis contains dendritic cells, macrophages, mast cells, T-cells, plasma cells, natural killer cells, natural lymphoid cells [32]. 
The main function of these cells is to identify pathogens entering the skin and to balance the host and skin microbiome [33].

Skin microbiota affects the innate immune responses in the skin by triggering the production of antimicrobial peptides (AMPS), complement system elements and interleukin-1 (IL-1). IL-1 production triggers the production of IL-17 and interferon-gamma from T-cells (34).

The skin has the capacity to distinguish between commensal microorganisms that form microbiota and pathogenic microorganisms. Although its mechanism is not known exactly, it has been thought to be achieved by dendritic cell modulation [33]. How commensal microorganism antigens are continuously recognized by the immune system is not yet known. It is thought to be possible with dendritic cell extensions, direct uptake by keratinocyte or antigen presenting cells, or by passive epidermal diffusion [34].

T-cell responses are important in interaction with the microbiota. In healthy skin, gamma-delta $(\gamma \delta) \mathrm{T}$ Iymphocytes and alpha-beta $\mathrm{T}$ lymphocytes are found in both epidermal and dermal layers. Apart from these, there are resident memory T-cells (Resident memory T: TRM), which have a strong and long-lasting effect, and Foxp3 + memory regulator $\mathrm{T}$ (Treg) cells located around the hair follicles. CD8+ TRM cells are found in the epidermis, CD4+ TRM cells are found in the dermiş [35]. Langerhans cells are normally involved in the formation of regulatory T-cells against self-antigens and microbiota and take part in providing tolerance [36].

In the neonatal period, the formation of Foxp3 + Tregs as a result of encountering commensal bacteria such as S. epidermidis is critical in the development of commensal-specific tolerance $[37,38]$. Some substances produced by S. epidermidis selectively inhibit S. aureus and group A streptococci [33]. Lipoteichoic acid, a product of $S$. epidermidis, inhibits TLR3 signaling by binding to toll-like receptor-2 (TLR2), one of the natural immune system receptors, during tissue damage; and thus reduces inflammation, promotes wound healing, and triggers IL-17A+ CD8+ T-cells to settle in the epidermis [39]. In addition, S. epidermidis colonization has been shown to be sufficient to trigger protective immunity against pathogenic Leishmania major infection [40]. It has been shown that Treg cells accumulate in the skin of mice treated with Vitreoscilla filiformis lysate, which is a gram negative bacterium, and IL-10 production is triggered [40].

Dectin-1, located in the stratum corneum, is a non-TLR beta-( $\beta$ )glucan PRR and is the most important PRR in antifungal immunity [41]. It triggers Th1 response against Candida albicans in the pathogenic form of pseudohyphae. It has been shown that IL-17Aproducing dermally located $\gamma \delta$ T-cells decrease and commensal bacterial colonization increases in germ-free mice skin $[42,43]$.
These cells provide IL-17A production in the early stage and it's important in protecting against S. aureus and C. albicans infections.

The skin microbiome is mostly controlled by AMPs and proteins induced by cytokines such as IL-17A and IL-22, produced by T-cells in the skin. The presence of CD1a restricted T-cells that produce high levels of IL-22, recognize natural autoantigens and respond to intrinsic lipids has been demonstrated in the skin. This suggests that microbiome-derived lipids may also be effective in the establishment and maintenance of T-cells in the skin [44].

The deterioration of the balance of the microbiota for any reason is called "dysbiosis" and this can lead to the emergence of some inflammatory and systemic autoimmune diseases. The activation status of the host, its genetic predisposition, the localization of a certain microbe and its association with other microbial members are effective in triggering the disease [45].

\section{Microbiata and Dermatological Diseases}

\section{Atopic Dermatitis}

Atopic dermatitis (AD) is a chronic inflammatory skin disease characterized by itching, xerosis and eczema attacks. Pathophysiology of $A D$ involves elements of fillagrin gene mutation, epidermal barrier dysfunction, changes in cellular immune response and environmental factors.

The "hygiene hypothesis", which shows that the development of allergy increases with the decrease of microbial contact in early childhood, has turned into the "biodiversity hypothesis" with the detection that the microbiome is much more diverse than is known [46]. The rapid decline of environmental biodiversity associated with development has been associated with the increase in the prevalence of inflammatory and especially allergic diseases. Microbiota diversity and immunomodulatory capacity decrease due to decrease in natural environmental biodiversity [47]. The longterm protective effect of early exposure to microbial agents may be due to epigenetic regulation of the epithelium or long-term effects on $\mathrm{T}$ and B cell programming [48].

Staphylococcal colonization of the skin has been found to be high in children with atopic dermatitis. S. aureus activates protease receptors to disrupt the epidermal barrier of $A D$ patients. It releases endotoxins and enterotoxins that stimulate mast cells and cause inflammation and dysregulation of keratinocytes. It also upregulates the production of type 2 cytokines such as thymic stromal Iymphopoietin, IL-4 and IL-13 [49]. High IL-4 and IL-13 consume AMPs produced by keratinocytes needed to control pathogenic organisms [50]. Thus, TLR2-mediated detection of $S$. aureus in Langerhans cells is impaired, causing a keratinocyte dysregulation and disruption of the skin microbiome [51]. 
In healthy skin, Staphylococcus epidermidis activates TLR2, which induces keratinocyte-induced AMP secretion. In addition, coagulase negative bacteria such as $S$. epidermidis, S. hominis, and $S$. lugdunensis secrete antimicrobials that limit S. aureus overgrowth and biofilm formation. This protective process is impaired when S. aureus is the dominant species in the skin. According to the studies S. aureus colonization was found to be more intense in the disease involvement areas and was found to be associated with exacerbations in the disease [52].

Apart from the skin microbiome, the gut microbiota is also important in the disease [46]. Decreasing diversity of the gut microbiome has also been reported to cause the development of atopic dermatitis [53]. It has been shown that in patients with atopic dermatitis, the number of Bifidobacteria leading a commensal life in the gut flora is lower [54]. It has been reported that the risk of developing atopic dermatitis is increased in patients with increased antibiotic use in the first two years of life [46].

In contrast to atopic individuals, it has been shown that the density of Acinetobacter species from the Gammaproteobacteria class and IL-10 production in peripheral mononuclear cells increase in direct proportion to healthy individuals. TLR2 activation by nonpathogenic bacteria has been shown to trigger the formation of tolerogenic dendritic cells and regulatory Tr1 cells and reduce atopic inflammation [39].

Due to the strong relationship between $\mathrm{AD}$ and microbiome, it is aimed to increase commensal microorganisms in treatment. In the study by Nakatsuji et al. [55], it was found that autologous microbiome transplantation of S. hominis and S. epidermidis was effective in controlling S. aureus overgrowth. In the study of Myles et al. [56], the addition of topical Roseomonas mucosa and Vitreoscilla filiformis bacterial lysate improved the inflammation and severity of eczema.

\section{Psoriasis}

Psoriasis is an inflammatory skin disease characterized by erythematous scaly plaques. Recent studies on psoriasis and microbiome have found differences in both skin and gut microbiome of psoriasis patients. In 2008, Gao et al. [57] reported an increase in the number of Firmicutes and a decrease in the number of Proteobacteria and Acinetobacter in psoriatic plaques when compared to non-lesional skin. In a study by Alekseyenko et al. [58] in 2013, an increase in the number of Staphylococci and a decrease in Proteobacteria (Cupriavidus spp., Schlegelella spp., Methylobacterium spp.) and Bacteroidetes (Flavisolibacter spp.) were found in psoriasis patients. Many studies have reported an increase in the number of Staphylococci, Streptococci and a decrease in the number of Cutibacteria in psoriatic lesions. In a similar study, an increase in the number of Corynebacterium, Cutibacterium,
Staphylococcus and Streptococcus and a decrease in the number of Firmicutes and Actinobacteria were found in lesional and nonlesional skin of psoriasis patients. It has been reported that there is a decrease in the variety of bacteria in both lesional and nonlesional skin of psoriasis patients compared to healthy controls [59]. In a study, Chang et al. [60] compared psoriasis patients with healthy controls and found that $S$. aureus colonization was increased in both lesional and non-lesional skin in psoriasis patients. In the same study, it was found that mice colonized with S. aureus stimulate the Th17 response more than mice colonized with S. epidermidis. They suggested that $S$. aureus increased proinflammatory cytokine release and inflammatory response in psoriasis patients. This suggests that the irregularity of the skin microbiome in psoriasis patients is not limited to lesioned skin, but affects the entire skin microbiome.

In addition, it has been determined that psoriasis patients differ not only in skin microbiome but also in gut microbiome. In a study comparing psoriasis and psoriatic arthritis patients with healthy controls, it was found that the colonization of Coprococcus genus, Akkermansia and Ruminococcus genera decreased [61]. In a study by Scher et al. [62], they found a decrease in the diversity of bacteria in the gut of patients with psoriatic arthritis and psoriasis. They found a decrease in Actinobacterium colonization in both groups compared to healthy controls. In the group of psoriasis patients, they reported that the high Firmicutes/Bacteroidetes ratio showed a positive correlation with the Psoriasis Area Severity Index score intralesional and topical, to C. acnes-induced lesions suppressed.

Although it has been suggested that psoriasis may be related to the changes in the composition of the skin-gut bacteria and that changes in the microbiome may trigger psoriasis, the different results obtained with different methods do not provide a definite evidence on psoriasis-microbiome relationship. For this reason, it has been suggested that psoriasis is not only due to changes in the microbiome, but also a combination of genetic and environmental factors.

\section{Acne}

The acne microbiome started in 1960 with culture-based studies and continues to gain momentum today. As a result of sequencing with metagenomic analyzes, Cutibacterium acnes was found to be dominant in the pilosebaceous units of both patients with acne and healthy individuals [63]. Cutibacterium, Staphylococcus and Malassezia species were isolated by PCR examination of acne follicles and a correlation was found with the number of Malassezia species on the skin surface and the number of inflammatory acne [64]. C. acnes causes tissue destruction by secreting lipase, porphyrins and proteases. There is a correlation between the amount of porphyrin in the hair follicle and the severity of acne. It has been shown that acne-associated type IA-2 strains produce more porphyrin and that porphyrin synthesis of these strains is increased with vitamin B12 
intake [65]. In C. acnes species in healthy skin, a gene (deoR) has been identified which suppresses porphyrin biosynthesis. These findings suggest that methods targeting the porphyrin biosynthesis pathway and the probiotic use of $C$. acnes species associated with healthy skin may be the new possible acne treatment options. In addition, in an in vitro study, it has been shown that skin microorganisms, especially S. epidermidis, have an inhibitory effect on the growth of $C$. acnes by making glycerol fermentation. The researchers later demonstrated in vivo that administration of succinic acid, both intralesional and topical, to $C$. acnes-induced lesions suppressed $C$. acnes-mediated inflammation [66].

\section{Rosacea}

Rosacea is a skin disease characterized by facial erythema, telangiectasia and/or inflammatory papules and pustules. Abnormal neurovascular activation, irregular release of inflammatory molecules and proliferation of microorganisms in the skin are blamed in the etiopathogenesis [67]. Although Demodex folliculorum is a mite that lives on healthy skin, an increase has been detected in patients with rosacea. It has been hypothesized that this mite's exoskeleton stimulates the release of pathogenic inflammatory mediators [68]. Helicobacter pylori is the most accused agent in the relationship between rosacea and gut microbiota [69]. Although the exact pathway between $\mathrm{H}$. pylori infection and rosacea has not been fully elucidated, studies suggest that it may act via proinflammatory virulence peptides, especially in those with gastrointestinal symptoms [70]. However, the relationship to $\mathrm{H}$. pylori and rosacea remains controversial, as other studies have failed to find a correlation between the two entities $[71,72,73,74]$. Whether dysbiosis occurs in response to rosacea or is a cause is still debated [75].

\section{Hidradenitis Suppurativa}

Although hidradenitis suppurativa (HS) is stated to be sterile at the beginning of the disease process, it is suggested that the microbiome of preclinical $\mathrm{HS}$ is also different due to the detection of less bacteria and biofilms in the nonlesional axillary skin of the patients compared to healthy individuals. Therefore, it has been suggested that HS should be considered in the spectrum of bacterial biofilm-based disorders [76].

\section{Conclusion}

Commensal microorganisms on the skin protect the skin from external factors like a shield with a symbiotic relationship. Disruption of this relationship plays a key role in the pathogenesis of different skin diseases. Today many studies on the roles of microbiota in etiopathogenesis of systemic and dermatological diseases ar ongoing, and attetion is drawn to its importance in protecting human health. As a result of these studies, the emergence of different microbiota-related treatment options is an evidence that demonstrates the importance of the issue on human health.

\section{Ethics}

Peer-review: Externally and internally peer-reviewed.

\section{Authorship Contributions}

Surgical and Medical Practices: D.D., E.E., Concept: E.E., I.Z., Design: E.E., Data Collection or Processing: E.E., Analysis or Interpretation: D.D., E.E., I.Z., Literature Search: D.D., Writing: E.E.

Conflict of Interest: No conflict of interest was declared by the authors.

Financial Disclosure: The authors declared that this study received no financial support.

\section{References}

1. Filyk HA, Osborne LC. The multibiome: the intestinal ecosystem's influence on immune homeostasis, health, and disease. EBioMedicine 2016;13:4654.

2. Turnbaugh PJ, Ley RE, Hamady M, Fraser-Liggett CM, Knight R, Gordon JI. The human microbiome project. Nature 2007;449:804-810.

3. Yan D, Issa N, Afifi L, Jeon C, Chang HW, Liao W. The Role of the skin and gut microbiome in psoriatic disease. Curr Dermatol Rep 2017;6:94-103.

4. Pillsbury DM, Shelley WB. Dermatology. Annu Rev Med 1954;5:363-388.

5. Lederberg J. Infectious history. Science 2000;288:287-293.

6. Human Microbiome Project Consortium. Structure, function and diversity of the healthy human microbiome. Nature 2012;486:207-214.

7. Cunha AJ, Leite ÁJ, Almeida IS. The pediatrician's role in the first thousand days of the child: the pursuit of healthy nutrition and development. J Pediatr (Rio J) 2015;91(Suppl 1): S44-S51.

8. Amenyogbe N, Kollmann TR, Ben-Othman R. Early-life host-microbiome interphase: the key frontier for immune development. Front Pediatr 2017;5:111.

9. Mueller NT, Bakacs E, Combellick J, Grigoryan Z, Dominguez-Bello MG. The infant microbiome development: mom matters. Trends Mol Med 2015;21:109-117.

10. Dominguez-Bello MG, Costello EK, Contreras M, Magris M, Hidalgo G, Fierer $\mathrm{N}$, Knight R. Delivery mode shapes the acquisition and structure of the initial microbiota across multiple body habitats in newborns. Proc Natl Acad Sci USA 2010;107:11971-11975.

11. Martin R, Makino H, Cetinyurek Yavuz A, BenAmor K, Roelofs M, Ishikawa E, Kubota H, Swinkels S, Sakai T, Oishi K, Kushiro A, Knol J. Early-life events, including mode of delivery and type of feeding, siblings and gender, shape the developing gut microbiota. PLoS One 2016;11:e0158498.

12. Rutayisire E, Huang K, Liu Y, Tao F. The mode of delivery affects the diversity and colonization pattern of the gut microbiota during the first year of infants' life: a systematic review. BMC Gastroenterol 2016;16:86.

13. Eidelman Al. Breastfeeding and the use of human milk: an analysis of the American Academy of Pediatrics 2012 Breastfeeding Policy Statement. Breastfeed Med 2012;7:323-324.

14. Urbaniak C, Angelini M, Gloor GB, Reid G. Human milk microbiota profiles in relation to birthing method, gestation and infant gender. Microbiome 2016;4:1. 
15. Jost T, Lacroix C, Braegger C, Chassard C. Impact of human milk bacteria and oligosaccharides on neonatal gut microbiota establishment and gut health. Nutr Rev 2015;73:426-437.

16. Cogen AL, Nizet V, Gallo RL. Skin microbiota: a source of disease or defence? Br J Dermatol 2008;158:442-455.

17. Grice EA, Segre JA. The skin microbiome. Nat Rev Microbiol 2011;9:244-253.

18. Scharschmidt TC, Fischbach MA. What lives on our skin: ecology, genomics and therapeutic opportunities of the skin microbiome. Drug Discov Today Dis Mech 2013;10:e83-e89.

19. Grice EA, Kong HH, Conlan S, Deming CB, Davis J, Young AC, NISC Comparative Sequencing Program; Bouffard GG, Blakesley RW, Murray PR, Green ED, Turner ML, Segre JA. Topographical and temporal diversity of the human skin microbiome. Science 2009;324:1190-1192.

20. Grice EA, Segre JA. The skin microbiome. Nat Rev Microbiol 2011;9:244-253.

21. Nakatsuji T, Chiang HI, Jiang SB, Nagarajan H, Zengler K, Gallo RL. The microbiome extends to subepidermal compartments of normal skin. Nat Commun 2013;4:1431.

22. Findley K, Oh J, Yang J, Conlan S, Deming C, Meyer JA, Schoenfeld D, Nomicos E, Park M; NIH Intramural Sequencing Center Comparative Sequencing Program, Kong HH, Segre JA. Topographic diversity of fungal and bacterial communities in human skin. Nature 2013;498:367-370.

23. Lacey N, Kavanagh K, Tseng SC. Under the lash: Demodex mites in human diseases. Biochem (Lond) 2009;31:2-6.

24. Kong HH, Segre JA. Skin microbiome: looking back to move forward. J Invest Dermatol 2012;132:933-939.

25. Leyden JJ, McGinley KJ, Mills OH, Kligman AM. Age-related changes in the resident bacterial flora of the human face. J Invest Dermatol 1975;65:379381.

26. Giacomoni PU, Mammone T, Teri M. Gender-linked differences in human skin. J Dermatol Sci 2009;55:144-149.

27. Akaza N, Akamatsu H, Sasaki Y, Takeoka S, Kishi M, Mizutani H, Sano A, Hirokawa $\mathrm{K}$, Nakata S, Matsunaga K. Cutaneous Malassezia microbiota of healthy subjects differ by sex, body part and season. J Dermatol 2010;37:786-792.

28. Staudinger T, Pipal A, Redl B. Molecular analysis of the prevalent microbiota of human male and female forehead skin compared to forearm skin and the influence of make-up. J Appl Microbiol 2011;110:1381-1389.

29. Zapata HJ, Quagliarello VJ. The microbiota and microbiome in aging: potential implications in health and age-related diseases. J Am Geriatr Soc 2015;63:776-781.

30. Pochi PE, Strauss JS, Downing DT. Age-related changes in sebaceous gland activity. J Invest Dermatol 1979;73:108-111.

31. Holmes CJ, Plichta JK, Gamelli RL, Radek KA. Dynamic role of host stress responses in modulating the cutaneous microbiome: implications for wound healing and infection. Adv Wound Care (New Rochelle) 2015;4:24-37.

32. Nestle FO, Di Meglio P, Qin JZ, Nickoloff BJ. Skin immune sentinels in health and disease. Nat Rev Immunoly 2009;9:679-691.

33. Mann ER, Smith KM, Bernardo D, Al-Hassi HO, Knight SC, Hart AL. Review: Skin and the Immune System. J Clin Exp Dermatol Res (Special Issue) 2012;S2:116.

34. Belkaid Y, Tamoutounour S. The influence of skin microorganisms on cutaneous immunity. Nat Rev Immunol 2016;16:353-366.

35. Suwanpradid J, Holcomb ZE, MacLeod AS. Emerging Skin T-Cell Functions in Response to Environmental Insults. J Invest Dermatol 2017;137:288-294.

36. Sanford JA, Gallo RL. Functions of the skin microbiota in health and disease. Semin Immunol 2013;25:370-377.
37. Scharschmidt TC, Vasquez KS, Truong HA, Gearty SV, Pauli ML, Nosbaum A, Gratz IK, Otto M, Moon JJ, Liese J, Abbas AK, Fischbach MA, Rosenblum MD. Wave of regulatory T cells into neonatal skin Mediates tolerance to commensal microbes. Immunity 2015;43:1011-1021.

38. Lai Y, Nardo AD, Nakatsuji T, Leichtle A, Yang Y, Cogen AL, Zi-Rong Wu, Hooper LV, Schmidt RR, von Aulock S, Radek KA, Huang CM. Commensal bacteria regulate TLR3-dependent inflammation following skin injury. Nat Med 2009;15:1377-1382.

39. Naik S, Bouladoux N, Linehan JL, Han SJ, Harrison OJ, Wilhelm C, Conlan S, Himmelfarb S, Byrd AL, Deming C, Quinones M, Brenchley JM, Kong HH, Tussiwand R, Murphy KM, Merad M, Segre JA, Belkaid Y. Commensaldendriticcell interaction specifies a unique protective skin immune signature. Nature 2015;520:104-108.

40. Naik, S, Bouladoux N, Wilhelm C, Molloy MJ, Salcedo R, Kastenmuller W, Deming C, Quinones M, Koo L, Conlan S, Spencer S, Hall JA, Dzutsev A, Kong H, Campbell DJ, Trinchieri G, Segre JA, Belkaid Y. Compartmentalized control of skin immunity by resident commensals. Science 2012;337:1115-1119.

41. Volz T, Skabytska Y, Guenova E, Chen KM, Frick JS, Kirschning CJ, Kaesler $S$, Röcken M, Biedermann T. Nonpathogenic bacteria alleviating atopic dermatitis inflammation induce IL-10-producing dendritic cells and regulatory Tr1 cells. J Invest Dermatol 2014;134:96-104.

42. Kashem SW, Igyarto BZ, Gerami-Nejad M, Kumamoto Y, Mohammed JA, Jarrett E, Drummond RA, Zurawski SM, Zurawski G, Berman J, Iwasaki AI, Brown GD, Kaplan DH. Candida albicans morphology and dendritic cell subsets determine T helper cell differentiation. Immunity 2015;42:356366.

43. Cho JS, Pietras EM, Garcia NC, Ramos RI, Farzam DM, Monroe HR, Magorien JE, Blauvelt A, Kolls JK, Cheung AL, Cheng G, Modlin RL, Miller LS. IL-17 is essential for host defense against cutaneous Staphylococcus aureus infection in mice. J Clin Invest 210;120:1762-1773.

44. Suwanpradid J, Holcomb ZE, MacLeod AS. Emerging Skin T-Cell Functions in Response to Environmental Insults. J Invest Dermatol 2017;137:288-294.

45. Belkaid $\mathrm{Y}$, Hand T. Role of the microbiota in immunity and inflamation. Cell 2014;157;121-141.

46. Marrs T, Flohr C. The role of skin and gut microbiota in the development of atopic eczema. Br J Dermatol 2016;175(Suppl 2):13-18.

47. Hanski I, von Hertzen L, Fyhrquist N, Koskinen K, Torppa K, Laatikainen T, Karisola P, Auvinen P, Paulin L, Mäkelä MJ, Vartiainen E, Kosunen TU, Alenius H, Haahtela T. Environmental biodiversity, human microbiota, and allergy are interrelated. Proc Natl Acad Sci USA 2012;109:8334-8339.

48. Lambrecht BN, Hammad H. The immunology of the allergy epidemic and the hygiene hypothesis. Nat Immunol 2017;18:1076-1083.

49. Nakatsuji T, Chen TH, Two AM, Chun KA, Narala S, Geha RS, Hata TR, Gallo TL. Staphylococcus aureus exploits epidermal barrier defects in atopic dermatitis to trigger cytokine expression. J Invest Dermatol 2016;136:2192-2200.

50. Hirasawa Y, Takai T, Nakamura T, Mitsuishi K, Gunawan H, Suto H, Ogawa T, Wang XL, Ikeda S, Okumura K, Ogawa H. Staphylococcus aureus extracellular protease causes epidermal barrier dysfunction. J Invest Dermatol 2010;130:614-617.

51. Di Domenico EG, Cavallo I, Capitanio B, Ascenzioni F, Pimpinelli F, Morrone A, Ensoli F. Staphylococcus aureus and the cutaneous microbiota biofilms in the pathogenesis of atopic dermatitis. Microorganisms 2019;7:9.

52. Tauber M, Balica S, Hsu CY, Jean-Decoster C, Lauze C, Redoules D, Ogawa T, Wang XL, Ikeda S, Okumura K, Ogawa H. Staphylococcus aureus density on lesional and nonlesional skin is strongly associated with disease severity in atopic dermatitis. J Allergy Clin Immunol. 2016;137:1272-1274.

53. Penders J, Thijs C, van den Brandt PA, Kummeling I, Snijders B, Stelma F, Adams H, van Ree R, Stobberingh EE. Gut microbiota composition and 
development of atopic manifestations in infancy: the KOALA Birth Cohort Study. Gut 2007;56:661-667.

54. Abrahamsson TR, Jakobsson HE, Andersson AF, Bjorksten B, Engstrand L, Jenmalm MC. Low diversity of the gut microbiota in infants with atopic eczema. J Allergy Clin Immunol 2012;129:434-440.

55. Nakatsuji TCT, Chen T, Narala S, Chun KA, Two AM, Yun T, Shafiq F, Kotol PF, A, Melnik AV, Latif H, Kim JN, Lockhart A, Artis K, David G, Taylor P, Streib J, Dorrestein PC, Grier A, Gill SR, Zengler K, Hata TR, Leung DYM, Gallo RL. Antimicrobials from human skin commensal bacteria protect against Staphylococcus aureus and are deficient in atopic dermatitis. Sci Transl Med 2017:9:eaah4680

56. Myles IAEN, Anderson ED, Moore IN, Kieh MD, Williams KW, Saleem A, Fontecilla NM, Welch PA, Darnell DA, Barnhart L, Sun AA, Gulbu Uzel G, Datta SK. First-in-human topical microbiome transplantation with Roseomonas mucosa for atopic dermatitis. JCI Insight 2018;3:e120608.

57. Gao Z, Tseng C, Strober BE, Pei Z, Blaser MJ. Substantial Alterations of the Cutaneous Bacterial Biota in Psoriatic Lesions. PLoS One 2008;3:e2719. Accessed on: 05 July 2019.

58. Alekseyenko AV, Perez-Perez GI, De Souza A, Strober B, Gao Z, Bihan M, Methé $\mathrm{BA}$, Blaser MJ. Community differentiation of the cutaneous microbiota in psoriasis. Microbiome 2013;1:31.

59. Visser MJE, Kell DB, Pretorius E. Bacterial dysbiosis and translocation in psoriasis vulgaris. Front Cell Infect Microbiol 2019;9:7.

60. Chang HW, Yan D, Singh R, Liu J, Lu X, Ucmak D, Lee K, Afifi L, Fadrosh D, John Leech JL, Vasquez KS, Lowe MM, Rosenblum MD, Scharschmidt TC, Lynch SV, Liao W. Alteration of the cutaneous microbiome in psoriasis and potential role in Th17 polarization. Microbiome 2018;6:154.

61. Sikara M, Stec A, Chabaszcz M, Knot A, Waskill-Burna A, Rokowska A, Olszwska M, Rudnicka L. Gut microbiota in psoriasis: An update rewiev. Pathogens 2020;9:463.

62. Scher JU, Ubeda C, Artacho A, Attur M, Isaac S, Reddy SM, Marmon S, Neimann A, Brusca S, Patel T, Manasson J, Pamer E, Littman DR, Abramson SB. Decreased bacterial diversity characterizes the altered gut microbiota in patients with psoriatic arthritis, resembling dysbiosis in inflammatory bowel disease. Arthritis Rheumatol 2015;67:128-139.

63. Fitz-Gibbon S, Tomida S, Chiu BH, Nguyen L, Du C, Liu M, Elashoff D, Erfe MC, Loncaric A, Kim J, Modlin RL, Miller JF, Sodergren E, Craft N, Weinstock GM, Li H. Propionibacterium acnes strain populations in the human skin microbiome associated with acne. J Invest Dermatol 2013;133:2152-2160.
64. Akaza N, Akamatsu H, Numata S, Yamada S, Yagami A, Nakata S, Matsunaga K. Microorganisms inhabiting follicular contents of facial acne are not only Propionibacterium but also Malassezia spp. J Dermatol 2016;43:906-911.

65. Johnson T, Kang D, Barnard E, Li H. Strain-level differences in porphyrin production and regulation in propionibacterium acnes elucidate disease associations. mSphere 2016;1:e00023-15.

66. Wang Y, Kuo S, Shu M, Yu J, Huang S, Dai A, Richard L Gallo RL, Huang $\mathrm{CM}$. Staphylococcus epidermidis in the human skin microbiome mediates fermentation to inhibit the growth of Propionibacterium acnes: implications of probiotics in acne vulgaris. Appl Microbiol Biotechnol 2014;98:411-424.

67. Wilkin J, Dahl M, Detmar M, Drake L, Feinstein A, Odom R, Powell F. Standard classification of rosacea: Report of the National Rosacea Society Expert Committee on the Classification and Staging of Rosacea. J Am Acad Dermatol 2002;46:584-587.

68. Jarmuda S, O'Reilly N, Zaba R, Jakubowicz O, Szkaradkiewicz A, Kavanagh K. Potential role of Demodex mites and bacteria in the induction of rosacea. J Med Microbiol 2012;61:1504-1510.

69. Bhattarai S, Agrawal A, Rijal A, Majhi S, Pradhan B, Dhakal SS. The study of prevalence of Helicobacter pylori in patients with acne rosacea. Kathmandu Univ Med J 2012;10:49-52.

70. Szlachcic A. The link between Helicobacter pylori infection and rosacea. J Eur Acad Dermatol Venereol 2002;16:328-333.

71. Argenziano G, Donnarumma G, Iovene MR, Arnese P, Baldassarre MA, Baroni A. Incidence of anti-Helicobacter pylori and anti-CagA antibodies in rosacea patients. Int J Dermatol 2003;42:601-604.

72. Szlachcic A, Sliwowski Z, Karczewska E, Bielanski W, Pytko-Polonczyk J, Konturek SJ. Helicobacter pylori and its eradication in rosacea. J Physiol Pharmacol 1999;50:777-786.

73. Sharma VK, Lynn A, Kaminski M, Vasudeva R, Howden CW. A study of the prevalence of Helicobacter pylori infection and other markers of upper gastrointestinal tract disease in patients with rosacea. Am J Gastroenterol 1998;93:220-222.

74. Son SW, Kim IH, Oh CH, Kim JG. The response of rosacea to eradication of Helicobacter pylori. Br J Dermatol 1999;140:984-985.

75. Jorgensen AR, Egeberg A, Gideonsson R, Weinstock LB, Thyssen EP, Thyssen JP. Rosacea is associated with Helicobacter pylori: A systematic review and meta-analysis. J. Eur. Acad. Dermatol Venereol 2017;31:2010-2015.

76. Kathju S, Lasko LA, Stoodley P. Considering hidradenitis suppurativa as a bacterial biofilm disease. FEMS Immunol Med Microbiol 2012;65:385-389. 